\title{
Hábitos en seguridad alimentaria de consumidores en Neiva
}

\author{
Food safety habits in consumers in Neiva
}

\author{
Nelson Gutiérrez ${ }^{[1]}$, Sair Giraldo Durango ${ }^{[2]}$ y Nini Johana Carrillo[ ${ }^{[3]}$
}

\begin{abstract}
Resumen
Los hábitos inherentes a la preparación, manejo y consumo de productos alimenticios pueden delimitar el nivel de riesgo al que se expone determinada comunidad. Teniendo en consideración lo anterior se propuso analizar conductualmente los consumidores de la ciudad de Neiva - Colombia, en función de su actitud frente al manejo de los alimentos durante la compra, preparación y almacenamiento de los alimentos en el hogar, una vez estos salen de la cadena de comercialización. La metodología en primera instancia buscó identificar aquellos hábitos, actitudes y aptitudes que en mayor medida afectan la salud alimenticia, mediante un estudio que permitió arrojar un diagnóstico sobre la actitud de los consumidores en estos aspectos y los puntos críticos durante la compra, almacenamiento y preparación en los hogares de la ciudad de Neiva. Para lo cual se adaptó un instrumento diseñado en la Universidad del Estado de Kansas, que fue aplicado a fínales del año 2012 e inicios de 2013 a 113 hogares en Neiva. Con los resultados de aplicación del instrumento se realizó un análisis estadístico descriptivo para determinar aspectos en los cuales hay deficiencias y que pueden incidir como causa de enfermedades de transmisión alimentaria (ETA), considerando que éstas se generan debido a costumbres conductuales deficientes desde el contexto de inocuidad y calidad. Para la segunda fase se propuso un muestreo microbiológico piloto en las superficies tanto animadas como inanimadas, identificadas en la etapa anterior como críticas y así corroborar con los hallazgos del análisis microbiológico.
\end{abstract}

Palabras clave: inocuidad alimentaria; conciencia de los consumidores; contaminación biológica.

\begin{abstract}
Food preparation, management and consumption habits can determine the levels of risk that a community is exposed to. With this in mind, we proposed to analyze the behavior of consumers in Neiva - Colombia, insofar as their attitudes to food management during purchase, preparation and storage in the home, and once the food leaves the supply chain. The methodology sought to identify the habits, attitudes and aptitudes that most significantly affect food safety, through a study that allowed a diagnosis of the attitude of consumers in such factors and the critical points during food purchase, storage and preparation in homes in Neiva. To do this, we adapted an instrument designed by Kansas State University, that was applied at the end of 2012 and beginning of 2013 to 113 homes in Neiva. Using these results, we undertook a descriptive
\end{abstract}

[1] Ph.D Tecnología de Alimentos. Profesor Universidad Surcolombiana. Av. Pastrana Borrero carrera $1^{\text {a }}$ Neiva. ngutierrezg@usco.edu.co

[2] Ingeniera Agrícola. Universidad Surcolombiana. Av. Pastrana Borrero carrera 1a Neiva. sairgiraldo@hotmail.com

[3] Ingeniera Agrícola. Universidad Surcolombiana. Av. Pastrana Borrero carrera 1a Neiva. ninijoha_91@hotmail.com

Recibido: 21 noviembre 2014 • Aceptado: 5 marzo 2015 
statistical analysis to determine aspects where there are safety and quality deficiencies, which could be the cause of foodborne diseases (FBD). For the second phase, we proposed pilot microbiological sampling on inanimate and animate surfaces, identified in the previous stage as critical, and as such corroborate the findings of the microbiological analysis.

Key words: food safety; consumer awareness; biological contamination.

\section{Introducción}

Las enfermedades de transmisión alimentaria o ETA, han sido catalogadas como uno de los principales factores de morbilidad, ocupan el quinto lugar en el ranking de mortalidad mundial para el periodo de 2000 2011 y el cuarto puesto en las proyecciones para 2015 (OMS, 2013), por esto son una de las mayores preocupaciones de los organismos de salud tal como declara la Organización Mundial de la Salud (OMS).

Dichas enfermedades son causadas comúnmente por organismos como: Salmonella, Clostridium spp., E. coli, Staphylococcus aureus, entre otros, que representan un gran y creciente problema de salud pública que se ha venido intensificando con el paso del tiempo aún a pesar de protocolos implementados en toda la cadena de suministro de alimentos como el HACCP Hazard Analysis and Critical Points (Ropkins \& Angus, 2000), debido a que son aplicados en la industria y no de forma doméstica, además diferentes estudios han demostrado que el lugar implicado con mayor frecuencia con ETAs es el hogar (Redmond \& Griffith, 2003; Fischer et al, 2006); frente a lo que las investigaciones apuntan que el riesgo de contaminación cruzada por superficies (Gorman et al, 2002) son el principal foco de infección en proporción considerable siendo la causa de esto la propagación de microorganismos de producto crudo, a manos, superficies y otros alimentos, lo que se presenta ampliamente en el ámbito doméstico.

Se han realizado investigaciones que sustentan tales hechos, como se ve reflejado en estadísticas de países como Alemania y España donde el 50\% de los brotes reportados de origen alimentario se observan en el hogar (Carrasco et al., 2011), por malos hábitos de compra, manejo y preparación; problemática que no es ajena a la sociedad Colombiana ya que los datos internacionales muestran concordancia con los publicados para el país, donde el Instituto Nacional de Salud(INS), para el periodo 9 de 2013, reporta el hogar como principal lugar de consumo implicado en brotes de ETA con 292 casos confirmados, frente a 60 casos correspondientes al se- gundo lugar (establecimiento educativo). Teniendo en cuenta tanto lo anterior como que la inocuidad es crucial para consumidores, la industria alimenticia, la economía y entes gubernamentales, se puede ver la relevancia y magnitud del problema, más al estimar reportes como los ofrecidos por Raspor en el 2004, citados por Jevšnik et al., en el año 2008, dónde se afirma qué: “el cálculo de casos anuales de salmonelosis y campilobacteriosis en Europa es probable que exceda los cinco millones, demostrando que las pérdidas económicas y humanas resultantes de las enfermedades transmitidas por los alimentos ya no pueden ser ignoradas”.

El panorama luce aun peor si se considera que las cifras para los países en desarrollo son mayores que para aquellos desarrollados, además de que: "nuevos patógenos de transmisión alimentaria están aún siendo descubiertos” (Raspor, 2004, citado por Jevšnik et al., 2008). La región latinoamericana experimentó al menos 6000 brotes de diversos tipos de enfermedades de origen alimentario entre 1993 y 2002, según las cifras ofrecidas por la Organización de las Naciones Unidas para la Agricultura y la Alimentación (FAO) y la Organización Mundial de la Salud(OMS). Estos brotes, junto a un número mayor todavía de casos aislados de enfermedades provocadas por los alimentos o el agua, causaron en la región unas 57000 muertes en 2004. Sin embargo, esta estimación se encuentra todavía muy por debajo de la incidencia real del problema, según los expertos (INS, 2010).

A pesar de las estadísticas que se puedan encontrar, Colombia presenta bajos niveles de notificación e investigación en seguridad alimentaria así como para procurar la conciencia de los consumidores en temas referentes a la inocuidad; sólo hasta el año 2000 se inicia en el país la vigilancia de los eventos aislados y brotes de ETA por medio del sistema SIVIGILA, adscrito al INS, Ministerio de Salud y Protección Social; para tal año se tienen un total de 2938 casos, número que fue en aumento de la siguiente manera: 2001(5381 casos), 2002 (6566 casos), 2003 (6218 casos), 2004 (6090 casos), 2005 (7941 casos), 2006 (8183 casos), 2007 (5336), 2008 (9727), 2009 (13161 casos), 2010 
(11589 casos), 2011(13961 casos) y 2012 (11836 casos) (INS, 2013).

Analizando detenidamente el reporte para el año 2012 se tiene que los niños de 5 a 14 años son los más afectados y de forma general existe mayor incidencia para el género masculino, con un porcentaje del 57\%, la relación entre género y ocurrencia de las enfermedades transmitidas por los alimentos juega un papel primordial y se cree está basada en que fundamentalmente la cultura delega en las mujeres las responsabilidades del hogar, haciéndolas más aptas para mantener el debido cuidado en sus hábitos alimenticios, mientras que deja a los hombres con una percepción más descuidada y por ende más vulnerables a este tipo de dolencias (Kendall et al., 2012).

En el periodo comprendido hasta septiembre de 2013 en el territorio nacional 519 brotes representados en el 52\% se dieron en el hogar (INS, 2013), por lo que después de recorrer los antecedentes mostrados, cifras y realidad del riesgo que representan las ETA es preponderante afirmar que la necesidad de evaluar los hábitos de consumo con el objetivo de estimar el estado actual de los consumidores como actores principales de la problemática y también como eslabón crucial para evitar que continúen incrementando los casos y brotes por enfermedades de este tipo degradando la salud de las personas puesto que al mismo tiempo causan daños y pérdidas económicas que pueden ser prevenibles al optimizar las prácticas de manejo de alimentos en el hogar y mejorar la conciencia del consumidor frente a los conceptos de inocuidad.

Por lo anterior, se propuso este proyecto de investigación como primer herramienta de diagnóstico conductual de la sociedad Colombiana y más específicamente para las personas de la ciudad de Neiva, respecto a la seguridad alimentaria. Lo anterior teniendo en cuenta que representa un estudio piloto en Colombia ya que si bien se han evaluado y tomado medidas de seguridad en la industria, una vez el producto sale del mercado toda la responsabilidad recae en el consumidor final, el cual puede no poseer realmente el conocimiento necesario o simplemente aunque el consumidor se preocupa no tiene hábitos que permitan asegurar que el alimento se mantenga seguro. Se realiza ésta evaluación ya que solo se puede mejorar aquello que se conoce y una vez determinados los puntos débiles en el manejo que da el consumidor se relacionan los resultados obtenidos con la realidad mundial para finalmente ser capaces de apuntar a proponer estrategias que ofrezcan soluciones a la problemática en cuestión.

\section{Materiales y métodos}

La metodología de forma general se divide en 3 etapas: la primera contempla la adaptación y aplicación del instrumento de evaluación que se aplica como herramienta fundamental en el desarrollo del proyecto en una muestra de 113 hogares, posteriormente los datos obtenidos son tabulados y analizados mediante estadística descriptiva (segunda etapa), finalmente se realiza un muestreo microbiológico para mesófilos, enterobacterias, hongos y levaduras en las superficies catalogadas como puntos críticos en la fase anterior.

\subsection{Aplicación de las encuestas o instrumento}

Para la primera etapa el instrumento o cuestionario sobre seguridad alimentaria que fue elaborado por el departamento de nutrición humana de la Universidad de Kansas y para ser aplicado en la ciudad de Neiva fue traducido y adaptado a los modismos de la sociedad huilense sin afectar el propósito del documento inicial, por el grupo de investigación AgroindustriaUSCO. Se recibió de parte de la Dra. Kadri Koppel (investigadora del Departamento de Nutrición Humana de la Universidad del Estado de Kansas), un instrumento en inglés en formato Excel conformado por 38 ítems en tres secciones de preguntas, la primera sección correspondía a preguntas introductorias que permitían decidir si el encuestado podría hacer parte del estudio, la segunda sección de evaluación de hábitos en seguridad alimentaria, en la cual se cuestionaba al interpelado sobre los hábitos relacionados a la compra, manejo y almacenaje de productos alimenticios, para así determinar qué prácticas son puntos críticos en la sociedad huilense para mantener o vulnerar la inocuidad de los alimentos; éste apartado incluye preguntas como: Cuando compra huevos ¿¿están refrigerados o a temperatura ambiente?, ¿Normalmente se lava las manos antes de cocinar?, entre otras. En términos generales se evaluó si se mantenía la cadena de frio, si se cocinaban o almacenaban los alimentos a las temperaturas y en condiciones adecuadas, si se aislaban correctamente productos cárnicos de otros para evitar la contaminación cruzada, si se lavaban entre usos utensilios claves como la tabla de picar y si el manipulador tenía y aplicaba el conocimiento para evadir riesgos, además de mantener una adecuada higiene personal y conductual. 
La tercera sección correspondía a la caracterización demográfica de la población estudiada.

Se seleccionó al azar una muestra de 113 consumidores mayores de 18 años residentes en Neiva (amas de casa y personas encargadas de la compra y preparación de alimentos en el hogar), a los cuales se les aplicó encuesta mediante visita directa en los hogares en diferentes barrios de la ciudad y en algunos casos en sitios de trabajo de madres trabajadoras.

\subsubsection{Análisis estadístico descriptivo}

La segunda fase consistió en la realización de un análisis estadístico descriptivo de los resultados de la aplicacióndel instrumento para obtener la información relevante y para la caracterización conductual de los consumidores, haciendo uso de la herramienta informática Excel.

\subsection{Contextualización de los resultados para la ciudad de Neiva con Estados Unidos, España y Tailandia}

Los principales resultados obtenidos en la aplicación del instrumento (en la ciudad de Neiva) fueron analizados y comparados con los resultados de la aplicación del mismo instrumento en los Estados Unidos, España y Tailandia, para así determinar la concordancia o discrepancia de los hábitos alimenticios de la sociedad huilense con los presentados por otros países.

\subsection{Análisis microbiológico}

En la última etapa se realizó un muestreo piloto exploratorio en 15 hogares en la ciudad de Neiva, analizando diferentes superficies: nevera, manos en manipuladores domésticos y tablas de picar. Tal estudio se planteó en función de las principales fuentes de contaminación cruzada en el hogar, con lo que se determina la presencia de microorganismos mesófilos, enterobacterias, mohos y levaduras, tratando de precisar los riesgos biológicos presentes en la preparación de alimentos potencialmente causantes de enfermedades de transmisión alimentaria. El tratamiento de las muestras microbiológicas recolectadas se efectúa en el Laboratorio de Procesos Agroindustriales de la Universidad, para posteriormente confrontar los resultados de ambas etapas.

El protocolo implementado corresponde a una adaptación de la guía proporcionada al cliente para muestreo microbiológico de superficies (PRIMUSLAB, 2013) que se describe a continuación:
Se tomaron 3 muestras por cada una de las 3 superficies objeto de estudio en los 15 hogares evaluados, para un total de 9 muestras por hogar que posteriormente destinan de la siguiente manera: de las tres muestras tomadas de la tabla de picar, una de ellas se sembró en Agar peptona caseína o Plate Count (PC), la que se destina para la identificación de mesófilos; la siguiente para recuento de mohos y levaduras, en Agar infusión cerebro - corazón (BHI). La última se destina para recuento de enterobacterias y se sembró en Agar bilis y rojo de violeta (VRBG). En el caso de la tabla de picar y la nevera se utiliza una plantilla que delimita un área de $100 \mathrm{~cm}^{2}$, mientras que para las manos simplemente se presta especial atención en lugares como bajo las uñas, entre los dedos y alrededor de la palma. Posteriormente se procede a transportar las muestras hasta el laboratorio para su correspondiente análisis en condiciones asépticas, (cada hisopo en un tubo de ensayo con agua de peptona esterilizada), en caja protectora y en un periodo inferior a 1 hora.

Cálculo y expresión de resultados: Para superficies inanimadas el número de colonias obtenidas se expresaron en UFC/ $\mathrm{cm}^{2}$ (unidades formadoras de colonias $/ \mathrm{cm}^{2}$ ) para las manos se expresaran los resultados como UFC/manos. La interpretación de los resultados se realizó según los criterios microbiológicos para superficies inanimadas y el límite de detección debe ser ?1 UFC/ $\mathrm{cm}^{2}$ si es en superficies regulares ó ? 1UFC/manos (PRIMUSLAB, 2013).

\section{Resultados y discusión}

\subsection{Resultados del análisis estadístico de la aplicación del instrumento}

Los resultados muestran que los consumidores en general tienen conocimientos en lo que a seguridad alimentaria se refiere, sin embargo este conocimiento en algunos casos no representa el comportamiento habitual real de las personas, ya que aunque continúan mostrando una conducta que pone en riesgo tanto su salud como la de aquellos que pertenecen a su núcleo familiar, puesto que las respuestas están influencias por lo que consideran deben responder, más no, lo que asiduamente describe su conducta, en otros casos se generan hábitos potencialmente riesgosos porque a pesar de conocer aquellas conductas higiénicas las consideran fastidiosas e innecesarias. En resumen se llega a la conclusión de que aquellas personas que configuran los hogares con 
hábitos más pobres en seguridad alimentaria, lo hacen porque desconocen las prácticas necesarias para mantener la inocuidad de los alimentos o porque simplemente no les interesa.

Después de analizados los resultados del instrumento se caracterizan los siguientes puntos críticos en los hábitos referentes a seguridad alimentaria por parte de los consumidores: mantener los huevos a temperatura ambiente, no guardar productos cárnicos a temperaturas adecuadas y perfectamente aislados para evitar la contaminación cruzada, no lavar la tabla de picar entre usos, no lavarse las manos con agua y jabón frecuentemente, no limpiar y lavar la nevera adecuada y frecuentemente, poco conocimiento para procurar el apropiado almacenaje, asegurar que la cocción se da a temperaturas seguras por el tiempo necesario, entre otros. A pesar de existir más aspectos evaluados, los anteriores son los más relevantes identificados con el estudio.

Los consumidores Huilenses encuestados de forma general muestran tendencias que permiten mantener la inocuidad, aunque con elementos que se deben mejorar; por otro lado se tiene aquellos consumidores que a pesar de ser minoría muestran hábitos poco saludables y potencialmente peligrosos.

Como ilustración de lo anterior se tienen datos donde se muestra que un porcentaje igual al $97 \%$ de los encuestados compran los huevos a temperatura ambiente, lo cual es un grave peligro en seguridad alimentaria por la contaminación a la que se exponen los huevos normalmente (los productos avícolas se conectan usualmente con salmonelosis según estudios como el de Carrasco et al., 2011) y que con las temperaturas adecuadas podrían incubar organismos patógenos. Sólo el 16\% de la población compra huevos refrigerados.

Otro de los puntos críticos para evaluar según los resultados del instrumento, fue el encontrado en la pregunta sobre, Cuando corta varios tipos de alimentos, tales como carne, verduras, huevos, pan, etc., ¿normalmente qué utiliza?, con las siguientes opciones; (1) la misma superficie para cortar y la lavo al final, (2) la misma superficie para cortar y la limpio entre usos, (3) la misma superficie para cortar y la lavo entre usos, (4) diferentes superficies para cada producto y (5) no utilizo superficie para cortar. En la figura 1 se muestra los resultados de esta pregunta y los porcentajes para cada una de las opciones:

Si se observa la figura 1, el 43\% de las personas utilizan la misma superficie para cortar y la lava al final, siendo esto un riesgo para la salud, pues se puede ocasionar o promover la contaminación cruzada de los alimentos, por residuos y microorganismos que pasen de unos a otros. Es importante tener una adecuada higiene, utilizar diferentes tablas para los

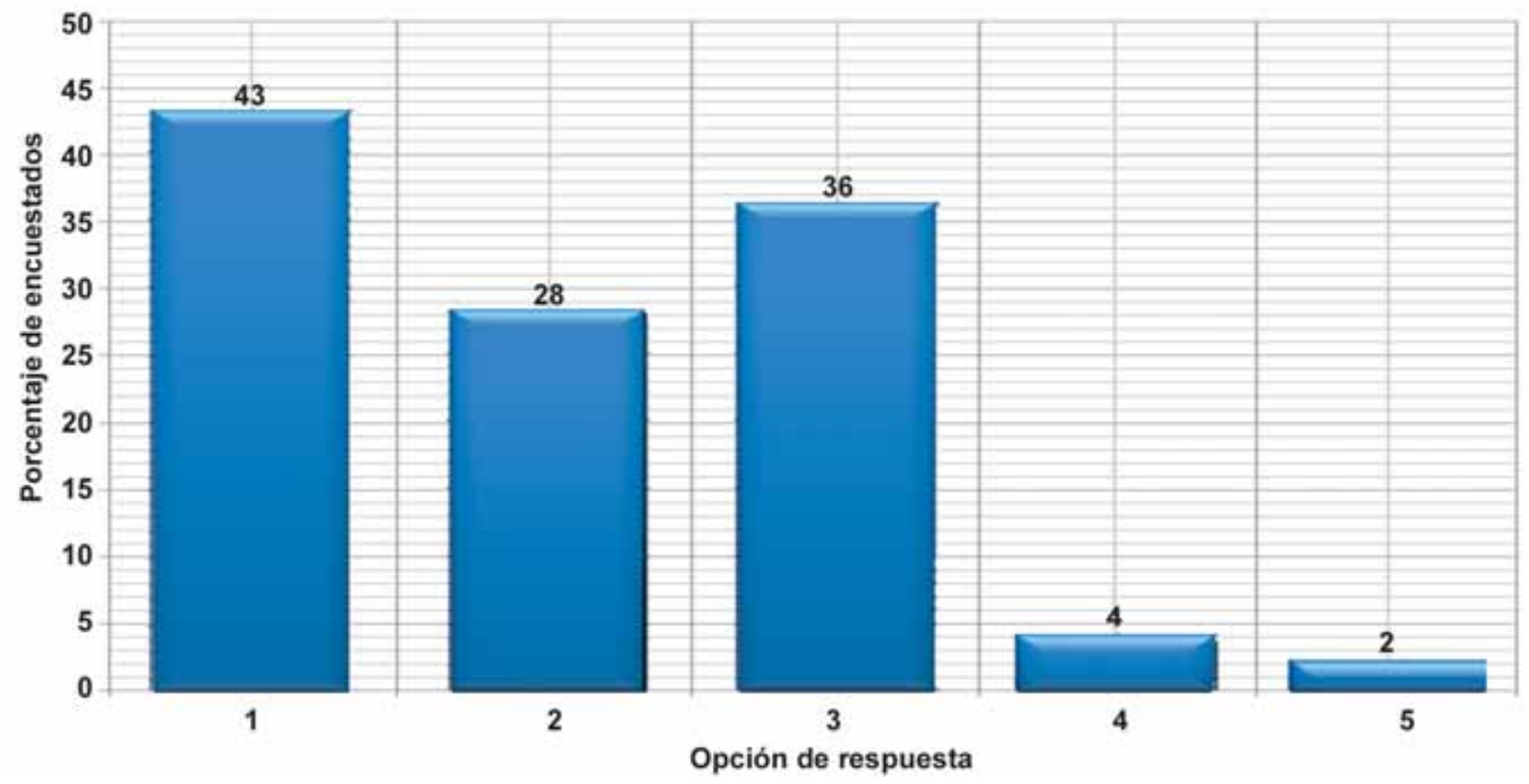

Figura 1. Relación de encuestados respecto a la forma de cortar diferentes tipos de alimentos. 
alimentos, especialmente para carnes y verduras ya que los microorganismos presentes en cárnicos podrían pasar fácilmente a vegetales (los que son consumidos sin mayores tratamientos térmicos que eliminen el peligro que representa la contaminación), generándose así casi inevitablemente el paso al ser humano y por consiguiente la posibilidad de desencadenar un episodio de ETA.

Con lo anterior se puede concluir que a pesar de las tendencias generales de la población, existe un porcentaje considerable que muestra hábitos deficientes para abordar la seguridad alimentaria en sus hogares, y aún aquellos que desarrollan conductas que aseguran de ciertas formas la inocuidad, presentan falencias en puntos que igualmente pueden revestir peligro para la salud.

\subsection{Contextualización de los resultados para la ciudad de Neiva con Estados Unidos, España y Tailandia}

Para realizar la comparación sobre los hábitos referentes a seguridad alimentaria en los países de Estados Unidos, España, Tailandia y Colombia, se integraron a este trabajo los resultados de la aplicación del mismo instrumento en Estados Unidos, España y Tailandia, remitidos desde el Departamento de Nutrición Humana y el Sensory Analysis Center de la Universidad del Estado de Kansas (KSU).

Los datos utilizados para la comparación corresponden a los resultados de un tamaño muestra igual a 116 en Estados Unidos, 102 en España y 100 en Tailandia. A continuación se presenta el análisis comparativo entre los países evaluados:

En la figura 2 se analiza la pregunta: ¿Cuándo sueles comprar huevos están refrigerados o a temperatura ambiente? (el color azul muestra el porcentaje de personas en cada país que afirma comprarlos refrigerados, mientras que el color rojo muestra el porcentaje de personas que los compra a temperatura ambiente. En este grafico se puede observar la gran diferencia que existe en los hábitos de compra entre residentes de Estados Unidos y los demás países, puesto que el primero alrededor del 99\% de los encuestados compran los huevos refrigerados, mientras que en España, Colombia y Tailandia la mayoría de personas compran los huevos a temperatura ambiente; de acuerdo a los peligros por contaminaciones del huevo, por bacterias patógenos que se pueden alojar en la cáscara de este; es muy importante saber que la mejor opción es comprar los huevos refrigerados, ya que esto ha permitido retrasar el crecimiento de las bacterias que pueden llegar a afectar el interior del huevo cuando las temperaturas son propicias para el crecimiento de microorganismos según lo afirman Carrascosa, 2011 y Carrasco et al., 2012.

En la figura 3 se muestran los resultados de la pregunta que interpelaba sobre qué hizo inmediatamente después de que manipulara carne, pollo, mariscos, o huevos, dándosele como opciones:

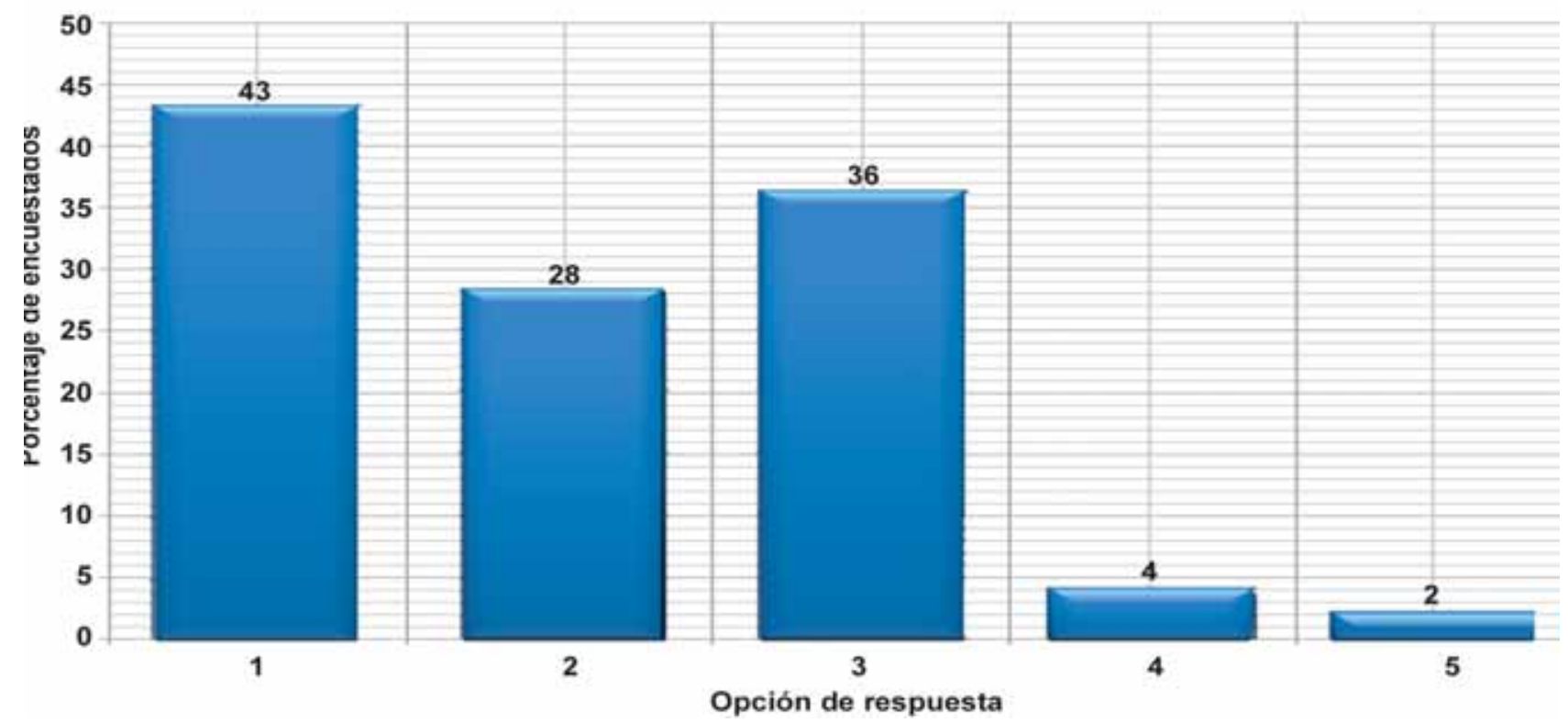

Figura 2. Comparativo de la temperatura a la que se compra usualmente ovoproductos en los 4 países estudiados. 


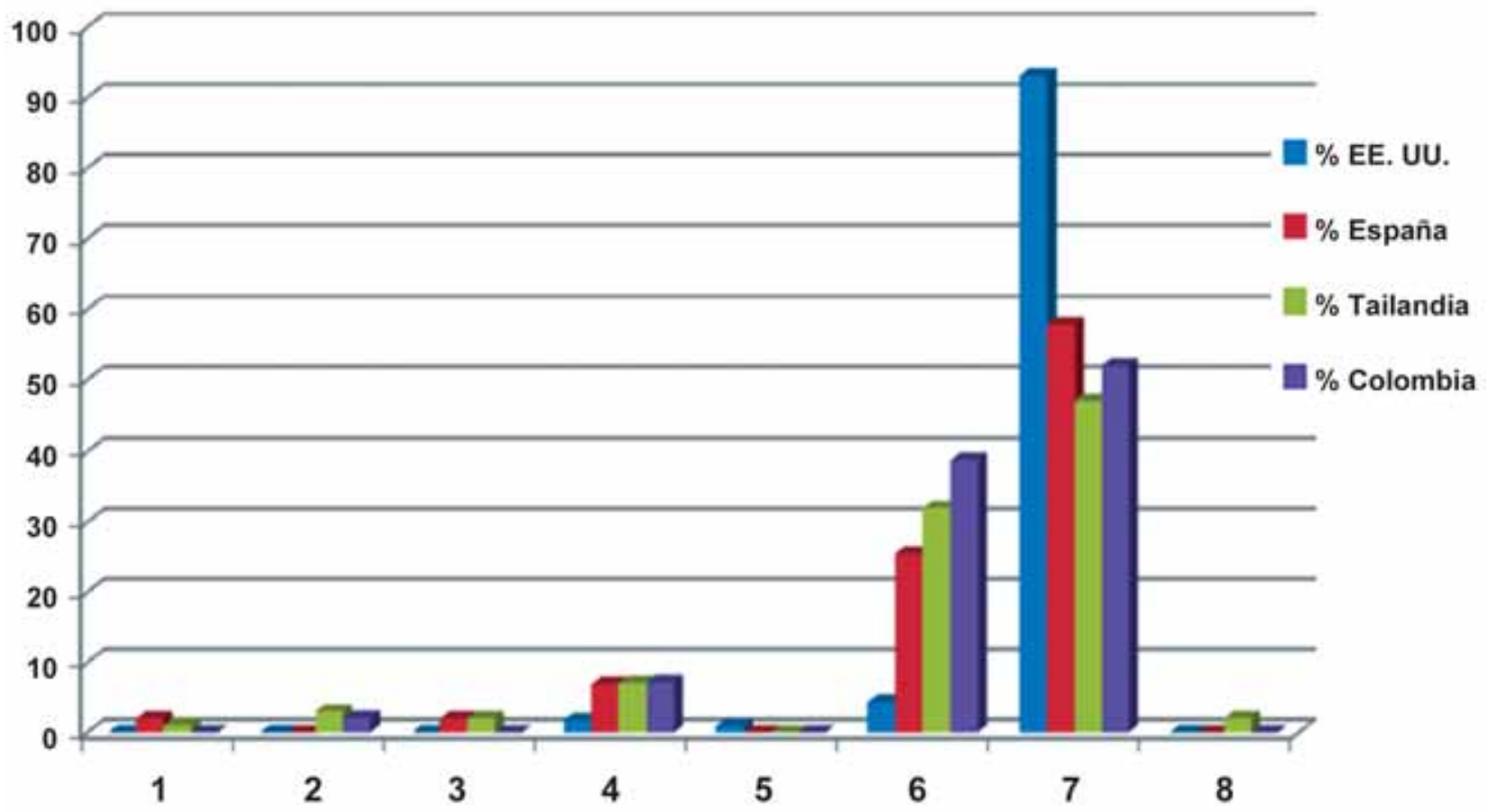

Figura 3. Potencial de contaminación cruzada en la preparación de alimentos.

1. Cortó algún otro alimento.

2. Tenía otros alimentos listos para cocinar pero no los cortó.

3. Tomó una olla para cocinar alimentos.

4. Se limpió las manos en una toalla de papel, paño de cocina, delantal o ropas.

5. Continúa cocinando sin limpiar, enjuagar o lavar las manos.

6. Enjuaga las manos, pero no utiliza jabón.

7. Lava las manos con agua y jabón.

8. No prepara carne, aves o mariscos.

Sobre la forma de lavarse las manos luego de manipular alimentos, se observa una similitud entre los cuatro países, en donde la mayor parte de los encuestados afirma lavarse las manos con agua y jabón pero en segundo lugar se tiene que usualmente las personas solo se enjuagan las manos y no utilizan jabón. Lo anterior representa un punto crítico que beneficia la contaminación cruzada puesto que lavar las manos sólo con agua no asegura que se han eliminado todos los microorganismos presentes.
Al observar los resultados anteriores se puede afirmar que si bien existen diferencias significantes en algunos aspectos entre los 4 países analizados, de forma general los huilenses presentan tendencias similares comparadas con España y Tailandia, mientras que diferencias substanciales con Estados Unidos, en aspectos como lugar de compra y refrigeración de productos como huevos, entre otros; lo que deja a la ciudad de Neiva en un punto intermedio en relación a los estándares mundiales.

\subsection{Resultados del análisis microbiológico}

Tal como se planteó en la metodología, finalmente se desarrolló un muestreo microbiológico piloto, para analizar superficies, detectadas como puntos clave para la contaminación cruzada en los hogares; según se hizo mención con anterioridad algunas de las practicas con mayor falencia en la sociedad es la de no lavar adecuadamente la tabla de picar entre usos, no lavar la nevera periódicamente y no lavarse las manos con agua y jabón de forma frecuente, por lo que dichas superficies hacen parte del estudio, para detectar el crecimiento general de mesófilos, enterobacterias, mohos y levaduras. Cabe resaltar que al momento de tomar las muestras se hacen anotaciones sobre el estado general de limpieza que se percibe en el hogar y más específicamente en las cocinas para así determinar si éste factor es relevante al cruzarlo con los resultados. 
Los resultados manifiestan crecimientos característicos del grupo de las enterobacterias en el medio Agar bilis y rojo de violeta, que cumplen con tales características: colonias color violeta, circulares (5mm de diámetro), bordes regulares, superficie convexa y en algunos casos se formaba un halo decolorado alrededor de la colonia, en relación con las observaciones realizadas con el microscopio se puede reconocer agrupaciones de cocos en racimo, Gram positivos.

Las tinciones provenientes de VRBG en las que se observó bacilos Gram negativos arreglados en empalizada provenían tanto de colonias color beige, perfectamente circulares de unos $3 \mathrm{~mm}$ de diámetro como también de colonias color violeta con un diámetro aproximado de $3 \mathrm{~mm}$.

Según los estudios de Gorman et al. (2002) y Azevedo et al. (2014) en ambientes domésticos existe la presencia de patógenos como: Staphylococcus coagulasa positivos, Salmonella, Clostridium perfringens, E. coli, Listeria spp. y Campylobacter spp., que además de ser potencialmente peligrosos algunos son de los más comunes encontrados en distintas superficies.

En algunas tinciones se evidencian características fenotípicas concordantes con las de los géneros anteriormente mencionados. Lo anterior también implica un nivel de riesgo elevado, si la flora bacteriana hallada, llegara a confirmarse específicamente como altamente patógena, aun así, con éstos resultados se muestra un rango de vulnerabilidad puesto que los crecimientos de organismos viales totales son considera- bles por unidad de área, y podrían pasar fácilmente de una superficie a otra o a productos alimenticios (contaminación cruzada). La secuencia de imágenes de la figura 4 corresponde en orden de aparición a placas sembradas con:

En primer lugar BHI (agar infusión cerebro - corazón), esta placa mostraba un crecimiento macroscópico circular uniforme, con bordes perfectamente redondeados, superficie convexa y color rosáceo de un diámetro de $4 \mathrm{~mm}$; al observar al microscopio las muestras tomadas de ésta colonia se identificó una morfología bacteriana correspondiente a cocos Gram positivos arreglados en racimo. Cabe anotar que el medio BHI se utilizó para favorecer el crecimiento de hongos pero también se dieron crecimientos bacterianos de microorganismos no exigentes.

La siguiente imagen corresponde a siembra realizada en PC (Plate count), proveniente de una colonia de forma irregular, con superficie plano convexa de $1 \mathrm{~cm}$ de diámetro y color blanco, de la cual al ser aislada una muestra se observan bacilos en cadena Gram positivos. El medio PC fue utilizado para mesófilos.

Las dos últimas imágenes corresponden a siembras en VRBG (selectivo para enterobacterias), en el primer caso la imagen corresponde a una colonia violeta de forma circular, de $5 \mathrm{~mm}$ de diámetro con bordes regulares y superficie convexa de la cual se aíslan cocos Gram negativos en racimo. Finalmente tenemos la imagen de la extrema derecha que corresponde a una colonia irregular de color violeta con $1 \mathrm{~mm}$ de ancho por $3 \mathrm{~mm}$ de largo y superficie plano-convexa, de

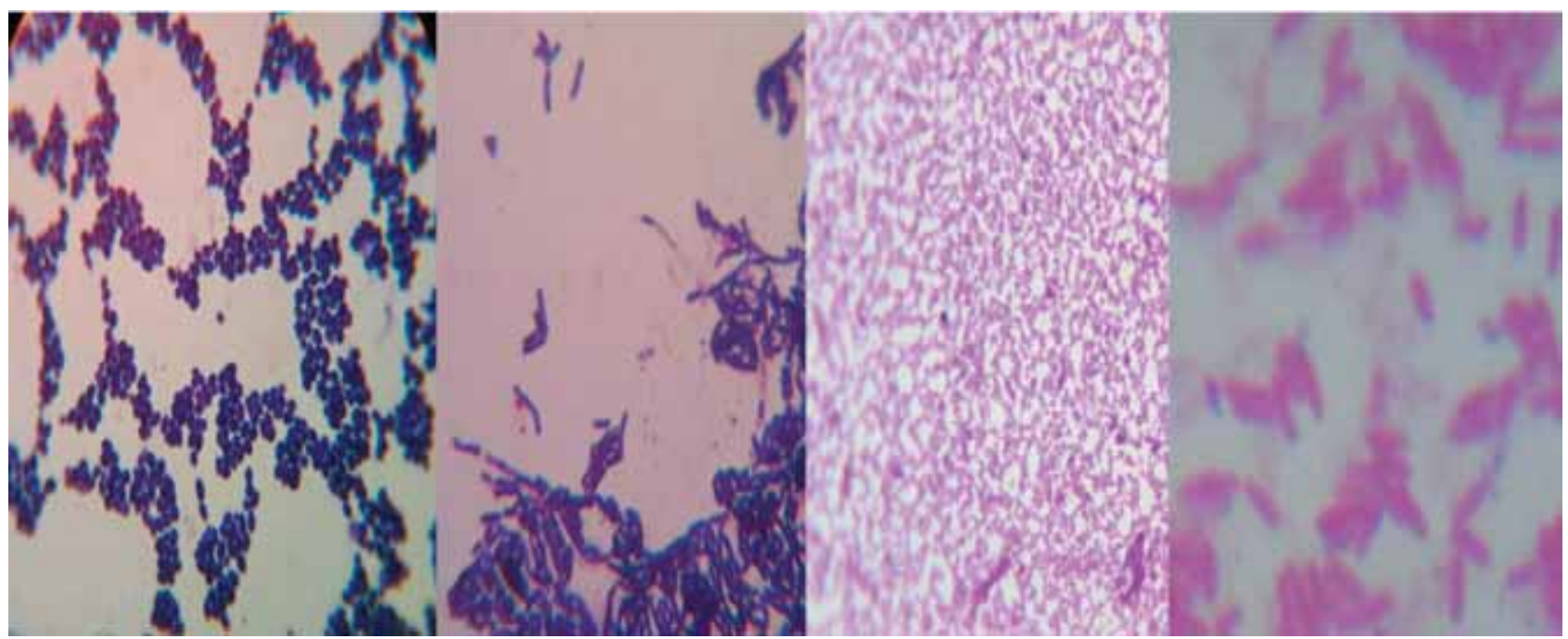

Figura 4. Morfologías de las bacterias observadas al microscopio después de la tinción de Gram. 
la cual se aíslan bacilos Gram negativos arreglados en empalizada.

El nivel de riesgo potencial al que la comunidad puede estar expuesto según revelan los resultados del muestreo piloto que se desarrolló, hasta aquí relacionados, pueden incrementarse al tener en cuenta que tal cual como se encontró en el análisis descriptivo y como ha sido documentado en estudios como el de Jevsnik et al., (2007), uno de los factores que menos parecen controlar los consumidores es la cocción a temperaturas seguras por el tiempo necesario, lo que resulta preocupante al contemplar que si bien existe una carga microbiana importante en las cocinas y que tales organismos se dispersan por las diferentes superficies notablemente fácil y rápido, hasta llegar a los alimentos, los mismos no son eliminados durante la preparación de las comidas, pudiendo generar así un episodio de ETA, con las respectivas implicaciones que esto representa.

Si se analiza lo anterior, cabe resaltar la necesidad de optimizar el conocimiento de los consumidores como garantes de la inocuidad de los alimentos, puesto que los organismos que resultan perjudiciales, son continuamente introducidos en el hogar por comidas contaminadas, mascotas, insectos, personas, suministros de agua y el aire (Gorman et al., 2002) y sin mayores conductas de control las cifras de incidencia de ETA pueden incrementar.

\section{Conclusiones}

- Se realizó un análisis estadístico descriptivo en donde se observó cómo esta Neiva a nivel de seguridad alimentaria y se concluye que aunque hay buenas prácticas de higiene en algunos hogares (o al menos dicen seguir buenas conductas), muchas personas aún no tienen claro ciertas prácticas adecuadas en aspectos como el almacenamiento de alimentos, tiempo de cocción, conservación de sobras de alimentos, higiene y limpieza de los utensilios de la cocina, entre otras.

- Los resultados de la aplicación del instrumento muestran que a pesar de que en su mayoría los consumidores reconocen el concepto de seguridad alimentaria y aquellas prácticas que ayudan a certificar la inocuidad, no siguen un comportamiento en concordancia con los planteamientos de los términos anteriores, lo que se confirma tanto a lo largo de cuestionario en aquellas preguntas de confirmación como en la visita a los hogares para la aplicación del muestreo microbiológico piloto.

- Entre las observaciones de riesgo más comunes en la aplicación del cuestionario y su respectivo análisis se detectaron malas prácticas de manipulación de alimentos (además de las ya mencionadas) como: el almacenar los huevos a temperatura ambiente, descongelar los alimentos en el mesón de la cocina, lavado e higienización de la nevera poco frecuente, entre otros que benefician la contaminación y proliferación de microorganismos en los alimentos. Lo anterior sin tener en cuenta el desconocimiento de las temperaturas y tiempos adecuados de cocción y almacenaje para eliminar patógenos y la peligrosidad que estos revisten, dejando ver que sin lugar a dudas el aseguramiento de la inocuidad en el hogar incluye diversos aspectos que sería simplemente dispendioso nombrar individualmente, pero que evaluando en conjunto la conducta de los consumidores, se concluye que la sociedad presenta hábitos deficientes en las prácticas de manipulación, tratamiento y conservación de los alimentos, lo que significa un riesgo para la salud humana.

- En el análisis microbiológico, también se observó que al efectuar una comparación con las observaciones durante la recolección de muestras en las casas, se puede concluir que en los hogares donde se encontró una mejor higiene aunque sí se presenta crecimiento, éste fue menor; mientras que en los hogares en donde las personas muestran conductas inadecuadas o deficientes en el contexto de la seguridad alimentaria, se dio un crecimiento mayor de colonias tanto de enterobacterias como de mesófilos. Con lo anterior se puede concluir que existe una relación directamente proporcional entre el nivel de conocimiento, calidad de hábitos en seguridad alimentaria y la carga microbiana total que se puede encontrar en un hogar y que puede llegar a ser potencialmente peligrosa para los habitantes del mismo.

- Al encontrar algunos de los puntos deficientes en los hábitos de los consumidores y confrontarlos con los resultados del montaje piloto de evaluación microbiológica, es posible vislumbrar la imperante necesidad de mantener no solo la limpieza sino la desinfección tanto en personas como en utensilios y equipos para evitar cualquier riesgo, ya que se comprueba que aún con los mejores hábitos existen menores densidades de población microbiológica potencialmente peligrosa. 
- Una vez analizada la situación mundial y contraponerla a la regional se puede concluir que por lo general Colombia, Tailandia y España muestran un significativo nivel de concordancia en cuanto a hábitos en seguridad alimentaria mientras que se pueden evidenciar algunas diferencias claves con los consumidores Estadounidenses.

\section{Referencias bibliográficas}

1. Azevedo, I., Albano, H., Silva, J., Teixeira, P. 2014. Food safety in the domestic environment. Food Control, 37 (1), pp. 272-276. http://www.scopus.com/ inward/record.url?eid=2-s2.0-84885450211 \&partnerID=40\&md5=b7663b3f797e5309878 ac37b239c3f20. DOCUMENT TYPE: Article. SOURCE: Scopus

2. Carrascosa A. 2011. ¿Qué sabemos de? los microbios que comemos. Madrid, España. CSIC. Los libros de la Catarata. 101p. ISBN (CSIC): 978-84-0009292-4. ISBN (CATARATA): 978-84-8319-581-9.

3. Carrasco, E., Morales-Rueda, A., \& García-Gimeno, R. M. 2012. Cross-contamination and recontamination by salmonella in foods: A review. Food Research International, 45(2), 545-556. Retrieved from www. scopus.com

4. Fischer, A. R., Frewer, L. J., \& Nauta, M. J. 2006. Toward improving food safety in the domestic environment: a multi-item Rasch Scale for the measurement of the safety efficacy of domestic foodhandling practices. Risk Analysis, 26,1323e1338.

5. Gorman, R., Bloomfield, S., \& Adley, C. C. 2002. A study of cross-contamination of food-borne pathogens in the domestic kitchen in the Republic of Ireland. International Journal of Food Microbiology, 76, 143-150. Retrieved from www.scopus.com.

6. Guía De Interpretación De Resultados Microbiológicos De Alimentos. http://www.anmat.gov.ar/alimentos/Guia_de_interpretacion_resultados_ microbiologicos.pdf Consultado el 15 de diciembre de 2013.

7. Guía Técnica sobre Criterios y procedimientos para el examen Microbiológico de superficies en Relación con Alimentos y Bebidas ftp://ftp2.minsa.gob.pe/ docconsulta/documentos/Proyecto.pdf consultado el 21 de Noviembre de 2013.
8. Instituto Nacional De Salud (INS). 2010. Informe Epidemiológico Nacional 2009. Subdirección de vigilancia y control en salud pública. Informe INS. Bogotá. Consultado el 22 de Septiembre de 2013.

9. Instituto Nacional De Salud. Informe del evento enfermedades transmitidas por alimentos, hasta el periodo epidemiológico 9 del año 2013. INS, proceso de vigilancia en salud pública. Bogotá D.C. FORR02.4000-001. Consultado el 3 de octubre de 2013. http://ins.gov.co/lineas-de-accion/Subdireccion-Vigilancia/Informe\%20de\%20Evento\%20Epidemiolgico/ ETA\%20Periodo\%20IX\%202013.pdf?Mobile=1\& Source $=\% 2$ Flineas-de-accion $\% 2 F$ SubdireccionVigilancia\%2F_layouts\%2Fmobile\%2Fmblwp.aspx\%3 FUrl\%3D\%252Flineas-de-accion\%252FSub direccion-Vigilancia\%252FPaginas\%252Finformesde-evento.aspx\%26CurrentPage\%3D1.

10.Jevšnik M., Hlebec V., \& Raspor P. 2008. Consumers' awareness of food safety from shopping to eating, Food Control, Volume 19, Issue 8, p. 737745, ISSN 0956-7135, http://dx.doi.org/10.1016/ j.foodcont.2007.07.017. (http://www.sciencedirect. com/science/article/pii/S0956713507001569). Retrieved from www.sciencedirect.com

11. Kendall H., Kuznesof S., Seal C., Dobson S. \& Brennan M. 2013. Domestic food safety and the older consumer: A segmentation analysis, Food Quality and Preference, Volume 28, Issue 1, Pages 396-406, ISSN 0950-3293, http://dx.doi.org/10.1016/ j.foodqual.2012.11.006. (http://www.sciencedirect. com/science/article/pii/S0950329312002224). Retrieved from www.sciencedirect.com

12. OMS. Organización Mundial De La Salud. 2013. Statistics. Global health estimates summary tables. Deaths by cause, age and sex by WHO region. Ginebra, Suiza. OMS.

13. OMS. Organización Mundial De La Salud. 2013. Statistics. Global health estimates summary tables. Projection of deaths by cause, age and sex. By world bank income group and WHO region. Ginebra, Suiza. OMS.

14. OMS. Organización Mundial De La Salud. 2013. Food safety. Foodborne Disease: A Focus for Health Education, 2000. Consultado el 9 de septiembre de 2013. http://www.who.int/foodsafety/publications/ capacity/fbd/en/ 
15. OMS: Organización Mundial De La Salud. 2007. Manual sobre las cinco claves para la inocuidad de los alimentos. Departamento de Inocuidad de los Alimentos, Zoonosis y Enfermedades de Transmisión Alimentaria. Francia. OMS. Clasificación NLM: WA 695.

16. Organización De Las Naciones Unidas Para La Agricultura Y La Alimentacion. 2009. Informe técnico sobre ingeniería agrícola y alimentaria. Enfermedades Trasmitidas por Alimentos y su impacto Económico-Estudios del Caso en Costa Rica, el Salvador, Guatemala, Honduras y Nicaragua. Roma. 194 p.

17.PRIMUSLAB. Primus Laboratorios De México, S. De R.L. De C.V. Guía para el cliente muestreo microbiológico de superficies. (On line). Primus Labs. http://www.primuslabs.com/spanish/services/ guia_de_muestreo_para_superficies.pdf. Consultado el 14 de noviembre de 2013.

18. Ropkins K., Beck J. A. 2000. HACCP in the home: a framework for improving awareness of hygiene and safe food handling with respect to chemical risk, Trends in Food Science \& Technology, Volume 11, Issue 3, Pages 105-114, ISSN 0924-2244, http:// dx.doi.org/10.1016/S0924-2244(00)00051-0. (http:/ /www.sciencedirect.com/science/article/pii/S092422 4400000510).

19.Redmond, E. C., \& Griffith, C. J. 2003. Consumer food handling in the home: a review of food safety studies. Journal of Food Protection, 66, 130e161. 
